\title{
ESKİ TÜRKLER ÇEK YAZAR MIYDI?
}

\section{Galip GÜNER*}

\section{$\ddot{O} z$}

Ticaret mekanizması aslında iki temel faaliyete bağlı olarak gerçekleşir: Satma ve alma. Bu bağlamda aslında temel yahut ikincil bir ihtiyacın karşılanması gayesine dayanan ticaret, Türklerde tarihin en eski dönemlerinden beri gerek iktisadi gerekse de siyasi ilerlemenin ana esaslarından birini oluşturmaktadır. Eski Türk devletlerinde yahut topluluklarında insanların gerek ellerinde bulunmayan malları başkalarından temin etme gerekse de ihtiyaç fazlası mallarını satarak gelir temin etme şeklinde cereyan eden ticari faaliyetleri hep olmuştur. $\mathrm{Bu}$ faaliyetler başlangıçta trampa yani değiş-tokuş esasına dayalı olarak gerçekleştiriliyorken (ki bu değiş-tokuşlarda Türkler çoklukla atı ve değerleri kürkleri kullanırlardı) sonraları hem başka milletlerden elde ettikleri bilhassa 7. yüzyıldan itibaren de altın, gümüş, bakır gibi değerli madenlerden kendi ürettikleri paraları kullanmaya başladılar. Devlet olmanın siyasi gücünü ticari faaliyetlerinde de devreye sokarak Uygurlardan itibaren kumaş ve kâğıt parayı da dolaşıma sokma başarısını gösterdiler. Ticaretin evrensel niteliği Türklerin Müslüman dünyaya dâhil olmasıyla ayrı bir boyut kazandı. Doğu Akdeniz’i önemli bir ticari coğrafyaya dönüştürmüş Müslüman tüccarların IX. yüzyıldan itibaren kullandıkları yeni bir ödeme sistemiyle karşılaştılar. $\mathrm{Bu}$, bir tüccarın vermiş olduğu siparişin bedelinin kendi hesabından ödenmesini kayıt altına alan yazılı bir belge niteliği taşıyan ve Farsça şāh kelimesinin farklı bir anlam ve kullanım boyutu kazanmasıyla ortaya çıkmış olan çak "çek" (> Ar. șakk) sistemi idi.

Bu çalışmada Farsça şāh > çāk > Türkçe çek kelimesinin 1356 tarihinde yazılmış olan Kitâbü'l-Ef'âl'den hareketle Türkçenin tarihî metinlerinde ilk defa tanıklanması konusuna değinilecek ve buradan hareketle eski Türklerin hukuki ve iktisadi bir belge olarak çeki kullanmaları konusu işlenecektir.

Anahtar Sözcükler: Ticaret, ödeme sistemleri, para, çek, Kitâbü’l-Ef’âl.

\section{WERE ANCIENT TURKS WROTE CHECK?}

\begin{abstract}
Commerce mechanism actually exists based on two main actions: Selling and buying. In this context, in fact, commerce, bounding to the aim of meeting a basic or a secondary need, has constituted the one of the main rudiments both economical and political development since the oldest time of the history for Turks. In old Turkish states or societies there were always commerce activities both supply the goods that they did not have from others and generate revenue by selling the surplus goods. While in the beginning these activities were done basing on the bartering namely exchanging (Turks
\end{abstract}

* Doç. Dr.; Erciyes Üniversitesi, Fen-Edebiyat Fak. Türk Dili ve Edebiyatı Bölümü, galip_guner@hotmail.com. 
used to use mostly horses and valuable furs in these barters), later on they started to use the coin gained from the other nations and especially since the 7th century they started to use the coins that they own produced from the valuable metals such as gold, silver and copper. With the help of the political power of being a state they succeeded in circulating rag money and fabrics money since Uigurs. The universal quality had a variant aspect with the partaking of the Turks in the Muslim World. They met a new payment system that the Muslim traders, who changed the East Mediterranean into an important commercial geography, used since 9th century. This was a çak 'check' (> Ar. sakk) system which emerged with acquiring dimension of a different meaning and usage of the word şāh in Persian and had the feature of written document recording to be paid from his account of the value of order which a merchant gone.

In this study, Persian $\check{s} \bar{a} h>c \bar{c} \bar{a} k$ and Turkish çek word recorded in Turkish history for the first time referenced to Kitâbü 'l-Ef'âl written in 1356 will be mentioned and from this point of view, the subject about the usage of the check of old Turks as a judicial and financial document will be had.

Keywords: Commerce, payment systems, money, check, Kitâbü'l-Ef'âl.

\section{Giriş:}

XI. yüzyılın başlarında Nasır-1 Husrev adında İranlı bir gezgin tüccar bugün de Irak’ın bir şehri olan Basra'yı ziyaret etti. Ziyaretinde șakk "çek" olarak bilinen bir ödeme biçimi ilk defa kayıtlara geçti. Bu ödeme biçimi, bir tüccarın vermiş olduğu siparişin bedelinin kendi hesabından ödenmesini kayıt altına alan yazılı bir belge niteliği taşımaktaydı (Quinn ve Roberds, 2008: 1). Bazı kaynaklar ise Müslüman tüccarların henüz IX. yüzyılda Halife Harun Reşid zamanında paranın transfer edilmesi amacıyla çeki yani sakk'1 kullandıklarını kaydetmektedir (Glubb, 1988: 105).

Batı dünyasında ise geçmişte iktisadi belge niteliğinde pek çok tarihî kayıt bulunmasına rağmen Müslüman dünyasının çeki kullandığı dönemlerde benzeri bir sistem henüz gelişmemiştir. Örneğin Roma İmparatorluğu'nda argentarii olarak bilinen ve banka gibi çalışan pek çok kurum olmasına rağmen argentarii müşterilerinin çek ya da benzeri bir belgeyi kullandığına dair hiçbir veri yoktur. Oysa Doğu Akdeniz'de tarihin ilk binli yıllarında çekin yaygın olarak kullanıldığı görülmektedir. X - XI. yüzyıllara gelindiğinde çeklerin Müslüman dünyasında artık yaygınlık kazandığı aşikârdır. Buna karşın aynı dönemde Avrupa'daki iktisadi sistemler son derece ilkeldir. Gerçek anlamda değeri olan sikkelerin sayısı son derece azdır, bankacılık ve çek sistemi ise hiç yoktur. Haçlı Seferleri esnasında Müslümanlarla temasa geçen Avrupalılar bu sayede Doğu Akdeniz'in bankacılık ve iktisadi sistemleriyle de tanışmışlardır. Böylece XIII. yüzyıldan sonra Barcelona, Floransa, Cenova ve Venedik gibi ticaret şehirlerinde ilkel bankalar kurulmaya başlar. Bu bankaların öncelikli amacı kredi sağlamak yerine yerel tüccarlar arasındaki ödemeleri kolaylaştırmak olur. Ödemeler sözlü olmaktan çıkıp yazılı yapılır. Ödeme yapmak için verecekli ve alacaklı birlikte bankaya giderek ödemelerini bankerler 
aracılığıyla gerçekleştirmeye çalışırlar. Bankacı, yapılan ödemeyi kayıt altına alarak aslında burada bir nevi noter vazifesi görür. İlk Avrupa bankaları çek kullanımına bir süre müsaade etmez. Bunda çeklerin karşılıksız çıkma ve alacaklının dolandırılma ihtimali etkindir. Orta Çağ bankacılığı zamanla her işlem için en az üç katılımcının ve iki şahidin varlığını gerektiren bir sistemi denemeye başlar. Mevduat hesaplarını bankanın kontrol edebilmesi ve ödeme sisteminin oluşabilecek riskleri denetleyebilmesi için hukuki bir süreç izlenir. İlk çekler Avrupa'da ancak Haçlı Seferleri'nden 200 yıl sonra 1400'lü yıllarda ve poliçe sisteminin gelişmesinin ardından görülür ve yavaş yavaş bankaların ödeme fonlarının büyümesi ve onlara olan güvensizliğin azalmasıyla çeklerin ödenmesi kolaylaşır. Modern anlamda çek sisteminin temelleri ise Avrupa'da ilk defa 1421 yılında bir Venedik bankasının ödemelerin kolaylaştırılması gayesiyle çekin kullanımına izin vermesiyle atılır (Quinn ve Roberds, 2008: 2-4).

X. yüzyılda Müslüman dünyasının ticari faaliyetlerinde çek $v b$. iktisadi unsurları kullandığına dair veriler ister istemez akla bu dünyanın bir parçası olarak Türklerin de çeki kullanıp kullanmadıkları sorusunu getirmektedir. Eski Türklerin iktisadi hayatı üzerine yapılan çalışmalar gerek Müslüman olmadan önce gerekse de olduktan sonra Türkler arasında iktisadi ödeme vasıtalarının çeşitliliğini açıkça gözler önüne sermektedir. Şöyle ki Eski Türklerin (Göktürk, Uygur ve Türgiş) sikkeleri üzerine yapılan çalışmalar 1890'l1 yıllarda Edmond Drouin'in çalışmalarıyla başlar. Drouin'in Turan Sikkeleri adlı çalışması Eski Türk ödeme biçimleri hakkındaki çalışmalara öncülük eder (Sertkaya ve Alimov, 2006: IX). Gerek Yenisey yazıtlarında ve arkeolojik kazılarda bulunan Eski Türk sikkeleri üzerinde rastlanan $a k c ̧ a v b$. genel terimler gerekse de Köktürk harfli yazıtlarda ve başta Moğolistan coğrafyası olmak üzere Türklerin yaşadığı bölgelerde ele geçen paralarda tespit edilen sarıg altun "sarı altın", ürüy kümüş “beyaz, parlak gümüş”, bakır gibi ibareler eski Türklerin iktisadi bir ödeme aracı olarak altını, gümüşü ya da bakırı kullandıklarının açık bir kanıtıdır. Bu konuda Sertkaya ve Alimov'un Eski Türklerde (Göktürklerde, Uygurlarda, Türgişlerde) Para adlı çalışmaları meseleyi aydınlatıcı boyutlarda bilgiler ihtiva etmesi bakımından önemlidir (Sertkaya ve Alimov, 2006, ayrica $b k$. Babayar, 2008).

XIII - XIV. yüzyıllarda yazıldıkları tahmin edilen Uygur sivil belgelerinde, kişiler yahut kişilerle devlet ya da kurumları arasındaki hukuki ve ticari sözleşmeleri ihtiva eden veriler ve ödeme usulleri ile araçları hakkında önemli bilgiler bulunmaktadır. Bu belgelere göre ticari faaliyetlerinde Uygurların, mal karşılığında mal veya hizmet karşı1ığı mal mübadelesi $v b$. ödeme yollarını tercih ettikleri gibi (Özyetgin, 2005: 152) bir ödeme aracı olarak kumaş (böz, kuanpo), madeni para (altun, kümüş, bakır) ve kâğıt para (çav) kullandıkları da bilinmektedir (Zieme, 1976: 246-247). Bu ödeme araçlarından böz "bez, pamuklu kumaş" daha çok arazi, 
gayrimenkul ve köle satış belgelerinde sıkça kullanılmıştır. Bezler aynı zamanda belirli idari bölgelerde geçerli olmak ve yönetim tarafından ödeme aracı olarak kullanılmak gayesiyle de mühürlenerek tescillenmişlerdi. Böz'ler gibi kuanpo'lar da (< Çin. kouon-pou) benzer amaçlar için kullanılıyordu. Uygur sivil belgelerinde tespit edilmemiş olan ancak Kâşgarlı Mahmud tarafından Dîvânü Lugâti 't-Türk'te kaydedilmiş bir diğer kumaş para da kamdu'dur. Kâşgarlı kelimeyi açıklarken "Dört arşın uzunluğunda, bir karış genişliğinde kumaş parçası. Üzerine Uygur hanının mührü basılır ve alışverişler onunla yapılır. Eskiyip yıprandığı zaman yedi yılda bir yamalanır, yıkanır ve üzerine mühür tekrar basılır." açıklamasını yapmaktadır (Ercilasun ve Akkoyunlu, 2014: 181). Zieme ve Özyetgin kamdu kelimesini kuanpo ve Uygur belgelerinde geçen varyantlarıla (kanpu kanpo) ilişkilendirirler (Zieme, 1976: 247; Özyetgin, 2005: 154).

Uygurların gündelik hayatta ve ticaret hayatında değerli madenleri paraya dönüştürerek kullandıkları da bilinmektedir. Altının, gümüşün ve bakırın değer bakımından yastuk "altın veya gümüş külçe", satır stır "sikke, para", bakır, bakır yarmak "bakır para" gibi birimlere ayrıldığ 1 ve kullanıldığı görülmektedir: 1 yastuk = 50 satır; 1 satır = 10 bakır (Özyetgin, 2005: 154-155).

Madeni paraların dışında Uygur sahasındaki bir diğer ödeme aracı ise çav yani kâğıt paradır. Çince çau (ch'ao) "kâğıt para" kelimesinden gelen çav, XIII. ve XIV. yüzyıllarda yazılmış Uygur sivil belgelerinde geçmektedir (Özyetgin, 2005: 157-158; Sertkaya ve Alimov, 2006: 73). Bunların dışında Uygurlar arasında ister iktisadi gayeyle isterse de başka bir amaçla gerçekleşmiş olsun her türlü hukuki işlemler için tanzim edilmiş vesikalar da (senet, makbuz, mukavele $v b$.) bir tasnife tâbi tutulmuş ve bitig, baş bitig, çın bitig, çın baş bitig, idiş bitig, öy bitig, buçuך bitig, yantut bitig, tutup turgu yanut bitig, ata bitigi, budun bitig, ötüg bitig, yarlig, ulam yarlıg, birtürü yarlıg, tuta turgu bitig, tuta turgu bitig yarlıg gibi oldukça detaylandırılmış tabirlerle ifade edilmiştir (Arat, 1987: 521-526).

Eski Türklerin iktisadi hayatının bir parçası olarak ödeme biçimlerinde görülen çeşitlilik Karahanlılar Dönemi’nde de devam eder. XI. yüzyılda Türk dünyasında, bilhassa da Selçuklu idaresindeki yerlerde alışveriş işlerinin Araplardan alınan dinar ve dirhem esasına göre düzenlenmiş paralar ile yapıldığı vakidir. Karahanlı hakanlarının da kendi hâkimiyet sahaları içinde geçerli olan paraları vardı (Genç, 1997: 295). Kâşgarlı'nın kayda geçirdiği verilerden anlaşıldığı üzere XI. yüzyılda yarmak denilen ve altın, gümüş, bakır gibi madenlerden yapılan normal ayarda paralara ilaveten düşük ayarlı paralar da bulunuyordu. Normal ayarda paraya bütün yarmak denilirken düşük ayarlı paralar ise eksik yarmak, buçuk yarmak gibi terimlerle adlandırılıyordu. Ayrıca böz'ün yani bez paranın XI. yüzyılda Türk dünyasında sadece Uygurlara ait bir ödeme sistemi olmadığı da Kâşgarlı'nın kayıtlarından anlaşılmaktadır. Zira 
yukarıda Uygurlara ait olarak zikrettiğimiz kamdu dışında Suvar Türkleri de egin denilen "eni bir buçuk karış, boyu ise dört arşın” gelen bir kumaşı para olarak kullanıyor ve bununla alışveriş yapıyorlardı (Genç, 1997: 296-297).

\section{2. İnceleme:}

Biz, bu çalışmada 18 Mart 1356 Cuma günü Mısır'da Abbâs ibni Hamza es-Sabrânî tarafından yazılmış olan ve Arapçadan Türkçeye ${ }^{1}$ bir sözlük niteliği taşıyan Kitâbül'l-Ef'âl'de geçen bir cümleden ve tamlamadan yola çıkarak eski Türk iktisadi hayatına ait bir veriyi kayıt altına almak istiyoruz: çek bitidi ạa fulān nirsege "Falanca şey için ona çek, senet yazdı." ve bu çek "bu çek" (48b 2, 3) (bk. Eminoğlu, 2011: 21).

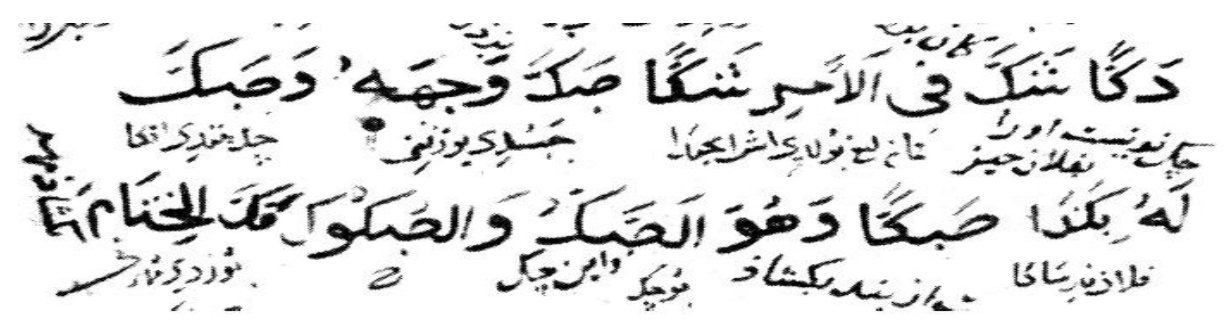

Kitâbü'l-Ef'âl, 48b-2, 3

Çek "senet, çek" kelimesinin Türkçenin Kitâbü'l-Ef'âl'in yazıldığı döneme kadar mevcut olan gerek hukuki gerekse de iktisadi belgelerinde tanıklanamamış olmasından, eserdeki bu kaydın bir ilk özelliği taşıdığını söyleyebiliriz. Kelime, Türkçenin daha sonraki dönemlerinde Çağatay ve Osmanlı Türkçesinde de kullanılmıştır. Örneğin Çağatay Türkçesinde çek 1. kura, emir. çek sal- "kur'a atmak" (Târiḩ-i Mulūk-i "Acem), çek tüş- "kurada çıkmak" (Târih-i Mulūk-i 'Acem); 2. defter, imza, şehadetname, tanık (Abuşka Lügati, Şeyh Süleyman Lügati, Bedayi'ü'l Vasat, Fevâyidü’l-Kiber), çek bol- “imzalamak, tanıklık etmek” (Fevâyidü'lKiber) olarak geçmektedir (Ünlü, 2013: 234).

Tulum, kelimenin XVII. yüzyıl Osmanlı Türkçesindeki kullanımını çek is. "el yazüsi, tezkere, temessük, sákk, dest-ḩátt” şeklinde göstermiştir (Tulum, 2011: 518). Ancak biz Meninski'nin çek konusundaki izahının da çalışmamız bağlamında önemli olduğunu düşünüyoruz. O, sözlüğünün çek (جك) maddesinde kelimenin Farsça (جكل) ve Arapça) olduğunu gösterdikten sonda $k \bar{a} z \bar{y}$ bitifi açıklaması yapar. Daha sonra bu açıklamasını genişleterek kelime hakkında "yargıcın görüşünü yazılı olarak belirttiği belge, yazılı bir garanti" bilgisine de yer verir (Meninski, 2000-I: 1629). Burhân-1 Katı’da ise Mütercim Âsım Efendi, çek (ج) kelimesinin dokuz anlamının olduğunu belirtmiştir. Bunlardan ilki onun yaptığı "berat, hüccet, temessük ve tapu tezkiresi manasındadır. Muarrebi sek’tir” açıklamasıdır ki bu çalışma

\footnotetext{
${ }^{1}$ Eserin başından 62. varağa kadar Arapça fiillerin hem Türkçe hem Farsça karşılıkları, kalan kısımda ise sadece Türkçe karşılıkları verilmiştir.
} 
bağlamında kelimenin Osmanlı sahasında da "berat, senet, borç senedi, resmî belge, tapu belgesi” anlamında kullanıldığını göstermesi bakımından önemlidir (Öztürk ve Örs, 2000: 133).

Çek kelimesinin tarihî gelişimi ve diller arası dolaşımı da son derece ilgi çekicidir. $\mathrm{Bu}$ bağlamda Nourai'nin ortaya koyduğu verilerin önemli olduğunu düşünüyoruz: Eski Farsça $x$ šây, $x \check{s} i$ "hüküm vermek, yetki vermek", x̌̌ača "kral, yönetici, hüküm veren, hâkim", x̌̌a-thra, xšathra "kralı olan, krallık" > Pehlevice šâh "kral, şah" > Farsça šâh "kral, şah" ve ardından fonetik bir değişikle aynı kelime čak "senet, çek" (Nourai, 1999: 248, ayrıca bk. MacKenzie, 1986: 79; Horn, 1892: 170). Nourai bu çalışmasında ayrıca çak > çek kelimesinin "senet, çek" anlamıyla X. yüzyılın ikinci yarısı ve XI. yüzyılın ilk yarısında yaşamış olan Firdevsi (M. 9401020) tarafından kullanılmış olduğunu da tespit etmiştir. Bu veri aynı zamanda makalenin giriş kısmında ortaya koyduğumuz Müslüman dünyasında çekin kullanımıyla ilgili bilgilerle de örtüşmektedir.

Farsça şāh > çak kelimesi daha sonra Arapçaya şakk (صَّ) "1. belge, tapu, senet, evrak, resmi yazı, belge, 2. çek” anlamıyla IX - XI. yüzyıllar arasında bir dönemde geçmiş (Nourai, 1999: 248) ve daha sonda şîk "çek" (شَّل) biçimini de almıştır (Baalbaki, 1995: 698). Kelimenin Batı dillerine geçişi Haçlı Seferleri ve Doğu Akdeniz'de ticaret yapan, sadece değerli malları alıp satmakla kalmayıp aynı zamanda kültürün ve bu bağlamda dil verilerinin de taşınması görevini üstlenmiş olan Müslüman veya Müslüman olmayan tüccarlar vasıtasıyla gerçekleşmiş olmalıdır. Zira kelime Arapça üzerinden Klein'e göre önce Orta İspanyolcaya (Klein, 1966: 272) kimi araştırmacılara göre de Vulgar Latincesine ve ardından diğer batı dillerine geçerek Vulgar Latincesinde scaccus "kral, şah", ardından Eski Fransızcada eschac ve daha sonra Yeni Fransizcada échecs (Brachet, 1873: 123, Stevenson, 2010: 296) olarak tespit edilmiştir. Fransızca üzerinden ise İngilizceye cheque ve check olarak alıntılanmıştır (Klein, 1966: 272). İngilizcedeki cheque söyleyişi Britanya kaynaklı bir söyleyiş biçimidir ve daha çok "çek" anlamında kullanılmaktadır (Klein, 1966: 273). Batı dillerinde kelime evvela "kral, şah" anlamıyla ve daha çok bir satranç terimi olarak kullanılmış, zamanla bankacılık sisteminin gelişimiyle doğru orantılı olarak XV. yüzyıldan itibaren iktisadi bir terim olarak kralın ya da mali gücü olan bir şahsın iktisadi işlemlerdeki garantörlüğünü ifade etmeye başlamıştır (Farsça $s ̧ \bar{a} h \sim$ çak $\rightarrow$ Arapça șakk $\rightarrow$ Vulgar Latince scaccus $\rightarrow$ Eski Fransızca eschac $\rightarrow$ Yeni Fransizca échecs $\rightarrow$ İngilizce cheque $\sim$ check).

Çek kelimesinin yayılmasıyla ilgili burada bir hususa ayrıca temas etmekte yarar görüyoruz. Yukarıda ortaya koyduğumuz verileri, aslında kelimenin doğuda ve batıda gelişimini, yayılımını ve diller arasındaki dolaşım süreciyle kazandığı anlamları iki boyutlu olarak değerlendirmek daha doğru olabilir. Şöyle ki Pehlevice şāh "kral, şah" kelimesi Farsçada 
yukarıda da değindiğimiz üzere hem fonetik bir değişmeye uğramış hem de çok anlamlılık kazanmıştır. Yani kelime hem "kral, şah" anlamıyla yaşamaya devam etmiş hem de çak biçimine değişerek "senet, çek" anlamını kazanmıştır. Biz, bu değişimin VIII - X. yüzyıllar arasında gerçekleştiğini düşünüyoruz. Kelime aynı dönemde iktisadi ve hukuki bir terim olarak Arapçaya şakk biçiminde "senet, belge, çek" anlamıyla da geçmiş olmalıdır. Batı dillerinde kelimenin iktisadi bir terim olarak kullanılması ise daha sonraları olmuştur.

$\mathrm{Bu}$ seyir içerisinde şarkın bir parçası olarak Türkler arasında da çak > çek kelimesinin kullanıldığı Kitâbü'l-Ef'âl' in tanıklığıyla ispatlanmaktadır. Arapçadan Türkçeye bir sözlük olan Kitâbü'l-Ef'âl' deki çek bitidi ała fulān nirsege "Falanca şey için ona çek, senet yazdı." ve bu çek "bu çek" $(48 \mathrm{~b} 2,3)$ ifadeleri ister hukuki isterse de iktisadi bir terim olarak kullanılmış olsunlar XIV. yüzyılda Harezm - Altınordu ve Memluk Kıpçak Türkleri nezdinde Türk dünyasında bu kelimenin bilindiğini ve kullanıldığını göstermesi açısından önemlidir. Bu yönüyle kelime tarihî Türk lehçeleri arasında bu anlamıyla ilk defa tespit edilmiştir. Meninski’nin ve Mütercim Âsım Efendi’nin verileri çek kelimesinin Osmanlı sahası nezdinde Batı Türkçesinde de "senet, borç senedi, tapu belgesi ve resmî belge" anlamında kullanıldığına işaret etmektedir. Bu durum kelimenin Türkçede Batı dillerinden çok daha erken bir dönemde hukuki ve iktisadi bir boyut taşıdığını da açıkça göstermektedir.

Karaağaç, Türkçenin Alıntılar Sözlüğü’nde çek kelimesini İngilizce check'ten getirir ve "Bir kimsenin bankadaki parasının dilediği kimseye ödenmesi için bankaya gönderdiği yazılı belge" olarak anlamlandırır (Karaağaç, 2015: 226). Karaağaç'ın kelimenin İngilizceden Türkçeye alıntılandığı yönündeki bu görüşünde temel gerekçe olarak kelimeyi modern bankacılık ilkeleri çerçevesinde değerlendirmiş olmasının yattığını düşünüyoruz. Meseleye bu yönüyle bakıldığında bu tercih doğrudur. Gerçekten de modern anlamda Osmanlı'da ilk banka 1847 yılında kurulmuş olan İstanbul Bankası'dır. İlk modern çek sahtekârlığı ise 1906 yılında Nicolas Eleftheris adlı bir Yunan vatandaşının kendi adına 10 bin, 12 bin ve 14 bin frank tutarındaki üç adet sahte Osmanlı Bankası çekini düzenleyerek bunlardan ikisini Bulgaristan'da iskonto ettirmesiyle gerçekleşmiştir (Eldem, 1997: 251). Ancak Kitâbü'l-Ef'âl'deki kayıttan bu yana tarihî Türk lehçelerinde çek kelimesinin kullanılmış olmasından mütevellid Karaağaç'ın ortaya koyduğu bilginin kelimenin Türkçeye çok geç girmiş ve kullanılmış olduğuna delalet etmemesi gerektiğini düşünüyoruz. Lakin açık olan bir husus vardır ki bu da çekin batıda XV. yüzyıldan itibaren kazandığı modern anlamıyla Türkçede yaygınlaşmamış olduğudur. Bunda bankacılık sisteminin Avrupa'da geliştiği biçimiyle Türkler arasında yaygınlaşmamış olmasının etkisinden söz edilebilir. Yani çek kelimesi XIV. yüzyılda iktisadi bir terim olarak Türkler 
arasında kullanılıyordu ancak zaman içinde kelime batıda farklı bir nitelik kazandı ve bu biçimiyle XIX. yüzyılda Osmanlı söz varlığındaki yerini yeniden aldı denilebilir.

\section{Kaynaklar}

ARAT, R. R. (1987). Eski Türk hukuk vesikaları. Makaleler, Cilt-I. Ankara: TKAE Yay. 506572. Yay. haz. Osman Fikri SERTKAYA.

BAALBAKİ, R. (1995). Al-Mawrid, a modern Arabic-English dictionary. Beirut: Dar el-i̇lm Lilmalayin Yay.

BABAYAR, G. (2008). Fergana vadisinde bulunan Türk-Runik yazılı Köktürk sikkeleri üzerine. Dünden Bugüne İpekyolu (Beklentiler ve Gerçekler). İstanbul: Ötüken Yay.

BRACHET, A. (1873). An etymological dictionary of the French language. Oxford: Clarendon Press.

ELDEM, E. (1997). 135 Ylllık bir hazine Osmanlı Bankası arşivinde tarihten izler. İstanbul: Tarih Vakfi Yurt Yay.

EMINOĞLU, E. (2011). Abbâs ibni Hamza es-Sabrânî-Kitâbü'l-Ef'âl (Kıpçakça satır arası sözlük). Ankara: Akçağ Yay.

GENÇ, R. (1997). Kaşgarlı Mahmud'a göre XI. yüzyılda Türk dünyası. Ankara: TKAE Yay.

GLUBB, J. B. (1988). A short history of the Arab peoples. New York: Dorset Press.

HORN, P. (1892). Grundriss der neupersischen etymologie, sammlung indogermanischer wörterbuch IV. Strassburg.

KARAAĞAÇ, G. (2015). Türkçenin alıntılar sözlüğü. Ankara: Akçağ Yay.

KLEIN, E. (1966). A comprehensive etymological dictionary of English language. AmsterdamLondon-New York: Elsevier Publishing Company.

MACKENZIE, D. N. (1986). A concise Pahlavi dictionary. London: Oxford University Press.

MENINSKI, F. M. (2000). Thesaurus linguarum orientalium Turcicae-Arabicae-Persicae. Mit einer Einleitung und mit einem türkischen Wortindex von Stanistaw Stachowski, Band 1. İstanbul: Simurg Yay.

NOURAİ, A. (1999). An etymological dictionary of Persian, English and OtherIndo-European languages. U.S.A., Xlibris.

ÖZTÜRK, M. ve ÖRS, D. (2000). Mütercim Âsım Efendi-Burhân-ı Katı. Ankara: TDK Yay.

ÖZYETGIN, A. M. (2005). Eski Türklerde ödeme araçları: kâğıt para çav’ın kullanımı üzerine. Orta Zaman Türk Dili ve Kültürü Üzerine İncelemeler, İstanbul: Ötüken Yay.

QUINN, S. ve ROBERDS, W. (2008). The evolution of the check as a means of payment: a historical survey. Economic Review, 93(4), 1-28.

SERTKAYA, O. F. ve ALIMOV, R. (2006). Eski Türklerde (Göktürklerde, Uygurlarda, Türgişlerde) para. İstanbul: Ötüken Yay.

STEVENSON, A. (2010). Oxford dictionary of English. Oxford: Oxford University Press.

ÜNLÜ, S. (2013). Çăgatay Türkçesi sözlüğü. Konya: Eğitim Yayınevi.

ZIEME, P. (1976). .Zum Handel im Uigurische Reich von Qoço. Altorientalische Forschungen IV, 235-249. 